\title{
Myocutaneous revascularization following graded ischemia in lean and obese mice
}

\author{
Ross M Clark' \\ Brittany Coffman² \\ Paul G McGuire ${ }^{3}$ \\ Thomas R Howdieshell ${ }^{1,3}$ \\ 'Department of Surgery, ${ }^{2}$ Department \\ of Pathology, ${ }^{3}$ Department of Cell \\ Biology and Vascular Physiology, \\ University of New Mexico Health \\ Sciences Center, Albuquerque, NM, \\ USA
}

This article was published in the following Dove Press journal: Diabetes, Metabolic Syndrome and Obesity:Targets and Therapy 30 September 2016

Number of times this article has been viewed

Correspondence: Thomas R Howdieshell Department of Surgery, MSCI0-56I0, University of New Mexico Health Sciences Center, Albuquerque, NM $87 \mid 3 I$, USA

Tel +I 505272644 I

Fax +l 5052720432

Email thowdieshell@salud.unm.edu
Background: Murine models of diabetes and obesity have provided insight into the pathogenesis of impaired epithelialization of excisional skin wounds. However, knowledge of postischemic myocutaneous revascularization in these models is limited.

Materials and methods: A myocutaneous flap was created on the dorsum of wild type (C57BL/6), genetically obese and diabetic (ob/ob, db/db), complementary heterozygous $\left(\mathrm{ob}^{+} /\right.$ $\left.\mathrm{ob}^{-}, \mathrm{db}^{+} / \mathrm{db}^{-}\right)$, and diet-induced obese (DIO) mice ( $\mathrm{n}=48$ total; five operative mice per strain and three unoperated mice per strain as controls). Flap perfusion was documented by laser speckle contrast imaging. Local gene expression in control and postoperative flap tissue specimens was determined by quantitative reverse transcription polymerase chain reaction (RT-PCR). Image analysis of immunochemically stained histologic sections confirmed microvascular density and macrophage presence.

Results: Day 10 planimetric analysis revealed mean flap surface area necrosis values of $10.8 \%$, $12.9 \%, 9.9 \%, 0.4 \%, 1.4 \%$, and $23.0 \%$ for wild type, $\mathrm{db}^{+} / \mathrm{db}^{-}, \mathrm{ob}^{+} / \mathrm{ob}^{-}, \mathrm{db} / \mathrm{db}, \mathrm{ob} / \mathrm{ob}$, and DIO flaps, respectively. Over 10 days, laser speckle imaging documented increased perfusion at all time points with revascularization to supranormal perfusion in $\mathrm{db} / \mathrm{db}$ and $\mathrm{ob} / \mathrm{ob}$ flaps. In contrast, wild type, heterozygous, and DIO flaps displayed expected graded ischemia with failure of perfusion to return to baseline values. RT-PCR demonstrated statistically significant differences in angiogenic gene expression between lean and obese mice at baseline (unoperated) and at day 10 . Conclusion: Unexpected increased baseline skin perfusion and augmented myocutaneous revascularization accompanied by a control proangiogenic transcriptional signature in genetically obese mice compared to DIO and lean mice are reported. In future research, laser speckle imaging has been planned to be utilized in order to correlate spatiotemporal wound reperfusion with changes in cell recruitment and gene expression to better understand the differences in wound microvascular biology in lean and obese states.

Keywords: diabetes, obesity, laser speckle contrast imaging, reperfusion

\section{Introduction}

A recent report by the World Health Organization documented that there are $>1$ billion overweight adults worldwide, and at least 300 million of these individuals are clinically obese. ${ }^{1}$ Obesity is a chronic disorder of metabolism associated with an increased risk of type 2 diabetes, cardiovascular disease, hypertension, stroke, and cancer. ${ }^{2}$ Diabetes and cardiovascular disease require years for clinical presentation. Therefore, animal models are important for studying the pathophysiologic effects of obesity. ${ }^{3}$

Genetically obese (ob/ob) and diabetes $(\mathrm{db} / \mathrm{db})$ mouse strains have been promoted as animal models of diabetes-impaired skin repair. ${ }^{4-6}$ Seminal studies using an excisional 
wound model in these mice identified mechanisms responsible for impaired reepithelialization including sustained inflammation, impaired angiogenesis, reduced collagen synthesis, and defective macrophage functions..$^{7-10}$ Previous research in $\mathrm{ob} / \mathrm{ob}$ and $\mathrm{db} / \mathrm{db}$ mice has focused on the diabetic phenotype of the animals which appears to be a function of their adipose tissue mass. ${ }^{11,12}$ However, no published report to date has investigated postischemic myocutaneous revascularization differences among lean and obese strains of mice. Therefore, the goal of this study was to examine the differences in wound revascularization in lean and genetically obese and diet-induced obese (DIO) mice using a myocutaneous flap model of graded ischemia as a stimulus for wound neovascularization.

\section{Materials and methods}

\section{Murine myocutaneous flap model}

All animals were treated humanely in accordance with the National Research Council's "Guide for the Care and Use of Laboratory Animals" as part of a protocol approved by the University of New Mexico's animal review committee (IACUC), who also approved this study. Male C57BL/6 (C57bL/6J; stock 664), db/db (BKS.Cg-Dock7 ${ }^{\mathrm{m}}+/+$ Lepr $^{\mathrm{db}} / \mathrm{J}$; stock 642), ob/ob (B6.Cg-Lep ${ }^{\text {ob } / J ; ~ s t o c k ~ 632), ~} \mathrm{db}^{+} / \mathrm{db}^{-}$(heterozygote control for $\mathrm{db} / \mathrm{db}$ ), and $\mathrm{ob}^{+} / \mathrm{ob}^{-}$(heterozygote control for ob/ob) mice, 12 weeks of age (Jackson Laboratory, Bar Harbor, MN, USA) were fed a standard grain-based diet (20185, Harlan Laboratories Inc., Indianapolis, IN, USA). DIO mice (male C57BL/6, aged 4 weeks at initiation of highfat diet, Jackson Laboratory) were fed a high-fat diet (60\% of calories from fat; TD.06414, Harlan Laboratories Inc.) using a standard protocol to reach comparable body weight compared to genetically obese mice over a 12 -week period. ${ }^{3}$ All mice were age matched for flap surgery at 12 weeks of age with the exception of DIO mice at 16 weeks of age due to the interval required to attain comparable weight to $\mathrm{db} / \mathrm{db}$ and $\mathrm{ob} / \mathrm{ob}$ mice. A total of 48 mice were used in the study, five operative mice per strain and three unoperated mice per strain as controls. Male mice were utilized to avoid the potential effects of the estrous cycle on wound healing. All operative mice underwent inhalation anesthesia with isoflurane $(1 \%-3 \%)$ via nose cone.

Following induction of anesthesia, back skin hair was removed using electric clippers, and the site was prepped with povidone-iodine and $70 \%$ ethanol. A precise peninsular flap ( $2 \mathrm{~cm}$ in vertical length and $1 \mathrm{~cm}$ in horizontal width) consisting of skin, adipose tissue, and panniculus carnosus muscle was surgically created by making three soft tissue incisions. Flap dimension and location precision were insured by optical projection of a computer-generated mask by a data projector (Epson model 534A, Seiko Epson Corp, Nagano, Japan), and the dimensions were confirmed by high-quality caliper. The flap was mobilized cranially prior to reapproximation to the back skin with 6-0 monofilament sutures. A single subcutaneous dose $(0.01 \mathrm{mg} / \mathrm{kg})$ of buprenorphine hydrochloride provided postoperative analgesia. Each animal was singly housed and received water and food ad libitum after surgery. ${ }^{13}$

At 0 hours (immediately following flap surgery), 2, 5 , and 10 days post-surgery, the dorsal flap was photographed for analysis using a Nikon 070 digital camera (Nikon Instruments, Melville, NY, USA) equipped with a macro lens and mounted on a tripod at consistent height. The percentage of viable flap surface area was computed using a standard planimetry method. ${ }^{14}$ Flap area index was calculated by dividing the measured flap surface area at a specific day by the immediate postoperative flap area to document the importance of skin and panniculus muscle necrosis on flap size. The muscle area index was calculated by dividing the flap viable panniculus carnosus muscle surface area at day 10 by the unoperated flap muscle area.

\section{Dorsal myocutaneous vascular anatomy by fluorescein isothiocyanate (FITC)-dextran perfusion}

Following isoflurane anesthesia, perfusion was performed via the left ventricle with $30 \mathrm{~mL}$ of warm phosphate-buffered saline (PBS) followed by $30 \mathrm{~mL}$ of $10 \%$ formalin containing $20 \mathrm{mg} / \mathrm{mL}$ FITC-dextran (Sigma Chemicals, Perth, Australia). The back skin including panniculus carnosus muscle was excised, placed epidermal-side down, and photographed using a fluorescence dissecting microscope (Leica MZ FLIII; Leica Microsystems, Wetzlar, Germany). ${ }^{15}$

\section{Laser speckle contrast imaging}

Following inhalation anesthesia, laser speckle contrast imaging was performed prior to flap creation, and at 0 hours, 2, 5, and 10 days after surgery, with the Full-Field Laser Perfusion Imager (Moor Instruments, Axminster, UK) in lowresolution/high-speed setting at a display rate of $25 \mathrm{~Hz}$, time constant of $0.3 \mathrm{~s}$, and camera exposure time of $20 \mathrm{~ms}$. Processing of the contrast images produced a scaled color-coded Live Flux image (red: high perfusion; blue: low perfusion) which correlated with the blood flow velocity in the tissue. ${ }^{15}$

Data were analyzed using Moor FLPI V3.0 PC Software (Moor Instruments). The flap was divided into cranial, central, and caudal regions of interest (ROIs) of equal-imaged 
surface area. Data from each ROI were exported to R Statistical Analysis software (R Foundation, Vienna, Austria). To characterize the baseline microvascular anatomy of lean and obese mice, perfusion data from the surgically created flap were selected and exported to Matlab R2013b software (Mathworks Inc., Natick, MA, USA). A three-dimensional surface plot was constructed from the matrix data with floor set to average preoperative perfusion to illustrate the flap changes relative to the unoperated state. ${ }^{13}$

\section{Morphologic analysis and immunohistochemistry}

Mice were sacrificed by $\mathrm{CO}_{2}$ inhalation without surgery (controls) and 10 days following flap surgery for tissue harvest and histologic examination. The specific ages of mice at euthanasia included 13.5 weeks (12 weeks of age at flap surgery, 1.5 weeks of study) for C57BL/6, heterozygous, and genetically obese mice. DIO mice were euthanized at 17.5 weeks (16 weeks of age at flap surgery, 1.5 weeks of study). Preoperatively, and at day 10, all mice were weighed using a precision scale (XP-600; Denver Instruments, Denver, CO, USA), and each mouse underwent serum glucose determination via tail vein blood sampling and measurement of glucose by glucometer (Onetouch Ultramini; Lifescan - Johnson and Johnson, Milpitas, CA, USA). Unoperated back skin (controls) or day 10 flap was excised using sterile technique and transversely bisected yielding a proximal and distal tissue specimen. Histology and isolated RNA were processed in two flap regions (proximal and distal) rather than three ROIs due to sample volume requirements. One-half of each specimen was fixed in IHC Zinc Fixative (BD Biosciences, San Jose, CA, USA) for $24 \mathrm{~h}$ and paraffin-embedded. Serial sections (4 $\mu \mathrm{m})$ were dewaxed and taken through graded ethanol, hydrated in PBS solution, and stained with hematoxylin and eosin (Vector Laboratories, Burlingame, CA, USA) for bright-field microscopy for the determination of panniculus muscle necrosis by image analysis. The remaining half of the harvested flap was immersed in $500 \mu \mathrm{L}$ of RNAlater RNA Stabilization Reagent (Qiagen, Valencia, CA, USA) and stored at $4{ }^{\circ} \mathrm{C}$ for later RNA isolation. ${ }^{16}$

Sections were incubated with primary antibody (rat anti-mouse CD-31, ab550274, 1:50; BD BiosciencesPharmingen; rat anti-mouse F4/80, ab6640, 1:300; Abcam Inc., Cambridge, MA, USA) for $1 \mathrm{~h}$ at room temperature in a humidified chamber. Subsequently, the sections were incubated with a biotinylated secondary antibody (antirat immunoglobulin horseradish peroxidase kit, 1:50; BD Biosciences-Pharmingen) or fluorescent secondary antibody
(Alexa Fluor 555, 1:500; Thermo Fisher Scientific, Waltham, MA, USA) for blood vessel and macrophage identity. ${ }^{14}$

\section{Microvascular density and macrophage quantification}

Vessel count and vascular luminal cross-sectional surface area of control back skin and flap tissues were determined by image analysis of CD-31 immunostained sections. Three high-power $(100 \times)$ fields per full-thickness flap biopsy and three biopsies per each proximal and distal section were analyzed (six sections per mouse) with total mean values reported. ${ }^{14}$

Quantification of macrophage presence in control and flap tissues was determined by the analysis of maximal fluorescent intensity of F4/80 immunostaining. Three high-power $(100 \times)$ fields per section and three sections per mouse were photographed using two-channel fluorescent microscopy (Axioskop; Carl Zeiss Microimaging, Jena, Germany). Captured images were analyzed for red fluorescent intensity (CY3), which was standardized to a background fluorescence for each slide. Maximal fluorescent intensity was reported $\left(\times 10^{3}\right)$ per square millimeter of flap tissue area. ${ }^{14}$

\section{RNA isolation and purity}

Tissue samples were homogenized using a rotor-stator (VWR Pellet Mixer; VWR, West Chester, PA, USA) and QiaShredder (Qiagen) biopolymer shredding system according to the manufacturers' instructions. RNA concentration was determined by the absorbance at $260 \mathrm{~nm}$ in a spectrophotometer (NanoDrop 2000; Thermo Fisher Scientific). RNA purity was confirmed by a spectrophotometric ratio $\left(\mathrm{A}_{260} / \mathrm{A}_{280}\right)$ of 1.9-2.1, and by sharp bands for $28 \mathrm{~S}$ and $18 \mathrm{~S}$ ribosomal RNA on agarose gel electrophoresis. ${ }^{15}$

\section{Gene expression}

The RT ${ }^{2}$ Profiler PCR Array System (SABiosciences, Frederick, MD, USA) was utilized to analyze the expression of a focused panel of genes. Mouse Angiogenesis Pathway Array (PAMM-024C) was used to examine the mRNA levels of genes involved in angiogenesis and inflammation according to the manufacturer's protocol. TaqMan gene expression analysis consisted of a specific pair of unlabeled polymerase chain reaction (PCR) primers and a TaqMan probe, with glyceraldehyde-3-phosphate dehydrogenase utilized as an endogenous housekeeping control.

Arrays were performed on unoperated back myocutaneous tissue RNA from five $\mathrm{db} / \mathrm{db}$ mice and five $\mathrm{db}^{+} / \mathrm{db}^{-}$mice (controls). The relative change in the expression of each 
gene was determined by first normalizing the value to the average of five housekeeping genes (beta glucuronidase, hypoxanthine guanine phosphoribosyl transferase-1, heat shock protein $90 \mathrm{kDa}$ alpha, glyceraldehyde-3-phosphate dehydrogenase, and beta actin). Changes in the expression of a particular gene between control and $\mathrm{db} / \mathrm{db}$ mice were quantified by comparing the difference in cycle threshold $\left(C_{t}\right)$ values $\left(\Delta \Delta C_{t}\right)$ after normalization. Values were used in the calculation of fold change only if their $\mathrm{C}_{t}$ value was $<35$, confirming expression. ${ }^{16}$

\section{Statistics}

All data are expressed as mean \pm standard error of the mean. Statistical analysis was performed with SPSS 15.0 software (SPSS Inc., Chicago, IL, USA). Differences among groups and between baseline and subsequent time points were determined with Student's $t$-test or repeated-measures analysis of variance with Tukey significant difference test used for post hoc analysis. All calculations and statistical analysis of the PCR array data were performed by accessing PCR Array Data Analysis Web Portal (available from: http://superarray. com/pcrarraydataanalysis.php). Differences were considered statistically significant when $P<0.05$.

\section{Results}

\section{Body weights and serum glucose values}

Preoperative mean weights of $\mathrm{C} 57 \mathrm{BL} / 6, \mathrm{db}^{+} / \mathrm{db}^{-}$, and $\mathrm{ob}^{+} /$ $\mathrm{ob}^{-}$lean mice were 25.9, 26.6, and $26.1 \mathrm{~g}$, respectively. Corresponding preoperative mean weights of $\mathrm{db} / \mathrm{db}, \mathrm{ob} / \mathrm{ob}$, and DIO obese mice were $46.0,49.4$, and $48.1 \mathrm{~g}$, respectively. In lean and obese groups of mice, there was no significant

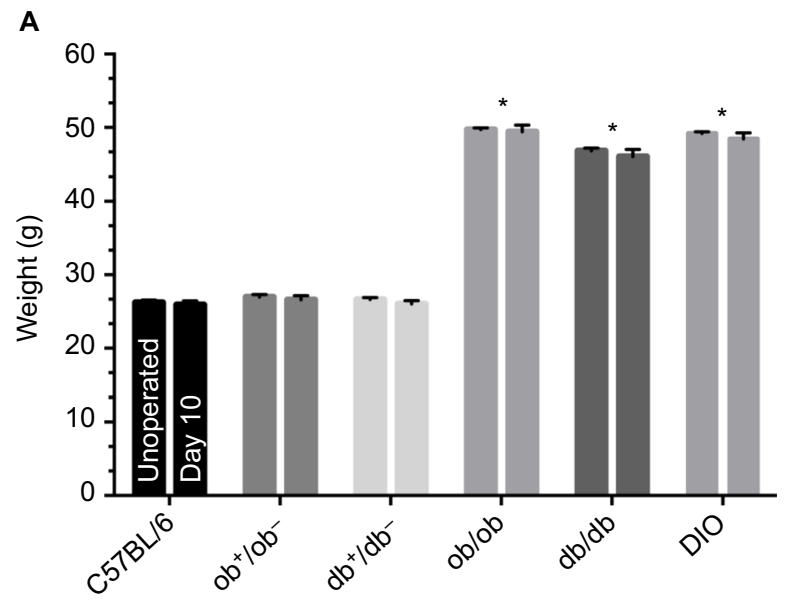

change in weight over the 10-day study period. Preoperative and day 10 mean serum glucose values of lean mice ranged from 167 to $192 \mathrm{mg} / \mathrm{dL}$. Preoperative and day 10 mean serum glucose values of obese mice ranged from 196 to $472 \mathrm{mg} /$ dL (Figure 1).

\section{Myocutaneous flap viability and histopathology}

Superficial blisters (epidermolysis) developed on lean mice (C57BL/6, $\mathrm{db}^{+} / \mathrm{db}^{-}$, and $\mathrm{ob}^{+} / \mathrm{ob}^{-}$) distal flaps beginning on day 2 . By day 10 , lean mice flaps were reduced in size due to distal myocutaneous necrosis, lack of flap engraftment, and resultant flap contraction. There was a dramatic reduction in viability and corresponding surface area of DIO flaps compared to wild type and heterozygous flaps. Epidermolysis of the distal portion of the flap with progression to fullthickness myocutaneous necrosis and dehiscence occurred in DIO mice by day 10 . In contrast, genetically obese (db/ $\mathrm{db}, \mathrm{ob} / \mathrm{ob}$ ) myocutaneous flaps engrafted to the recipient bed resulting in negligible contraction and near complete skin and muscle viability (Figure 2). Histopathology revealed that the contraction in the size of lean and DIO flaps occurred as a consequence of the lack of distal flap engraftment, poor neovascularization, cutaneous and panniculus carnosus muscle necrosis, and proliferation of the surrounding back skin epidermis producing elevation of the distal flap eschar and resultant epithelial closure of the residual wound by secondary healing. Minimal contraction was evident in genetically obese flaps due to extensive neovascularization of skin and panniculus muscle and complete flap engraftment to the recipient bed (Figure 3).

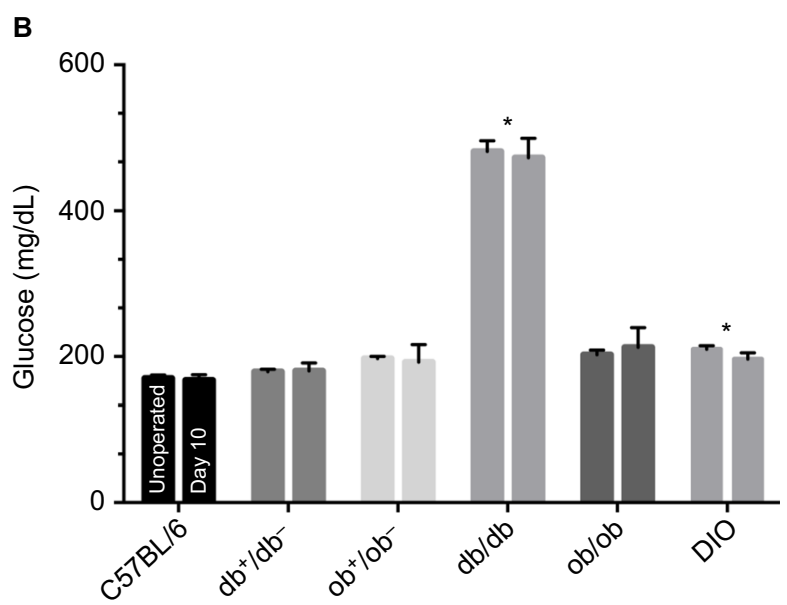

Figure I Preoperative and day 10 weights $(\mathbf{A})$ and serum glucose values $(\mathbf{B})$ of lean and obese mice.

Notes: ${ }^{*}<0.05$ versus C57BL/6 or respective heterozygous control. Mice types: C57BL/6, wild type; ob/ob, db/db genetically obese and diabetic; ob ${ }^{+} / b^{-}$, $\mathrm{db}^{+} / \mathrm{db}^{-}$, complementary heterozygous; DIO, diet-induced obese. 


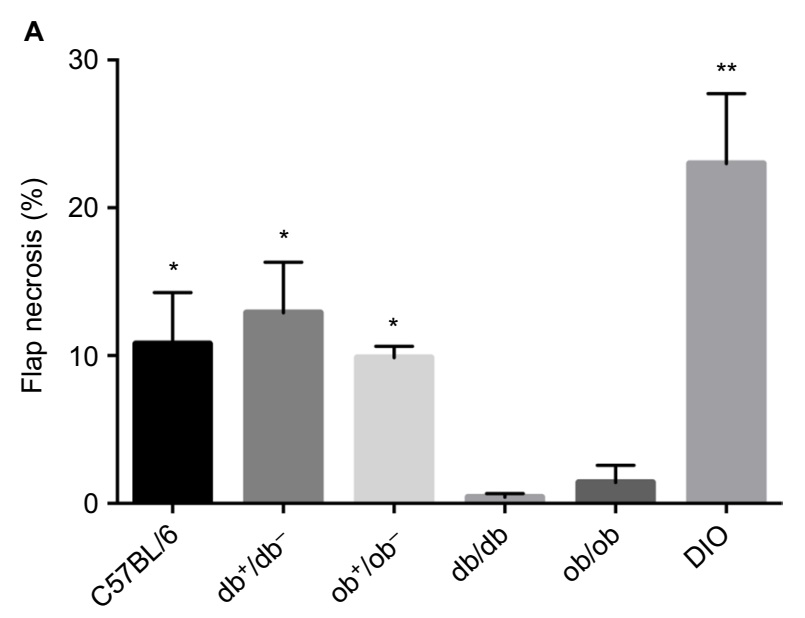

B

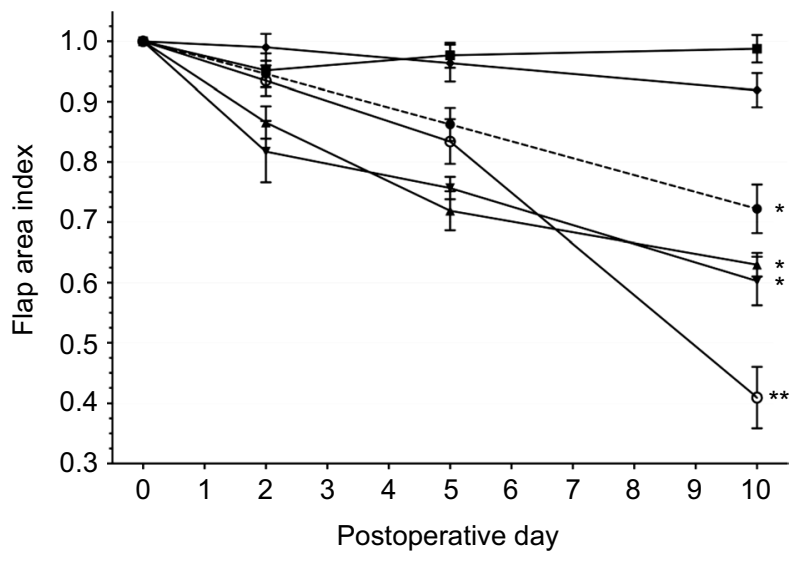

$+\mathrm{db} / \mathrm{db} \rightarrow \mathrm{ob} / \mathrm{ob} \cdot \mathrm{C} 57 \mathrm{BL} / 6+\mathrm{ob}^{+} / \mathrm{ob}^{-}+\mathrm{db}^{+} / \mathrm{db}^{-} \rightarrow \mathrm{DIO}$

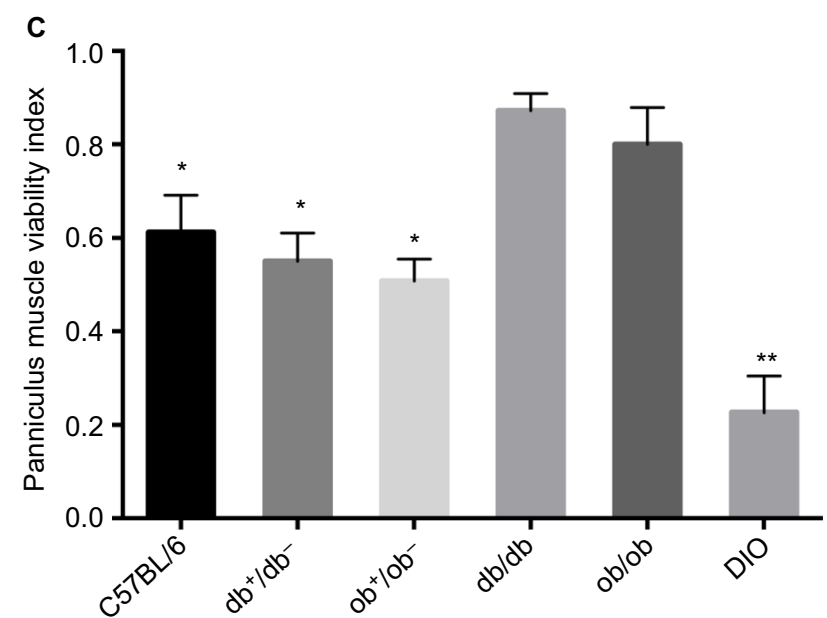

Figure 2 Myocutaneous flap viability.

Notes: (A) Planimetric determination of the percentage of necrotic flap surface area at day 10 ( $* P<0.05$ versus $\mathrm{db} / \mathrm{db}$ and ob/ob mice; $* * P<0.05$ versus $C 57 B L / 6$ mice). (B) Flap area index versus time illustrating the importance of skin and panniculus muscle necrosis on flap size $(* P<0.05$ versus $\mathrm{db} / \mathrm{db}$ and ob/ob mice at day $10 ; * * P<0.05$ versus C57BL/6 mice at day 10). (C) Panniculus muscle viability at day 10 ( $* P<0.05$ versus $\mathrm{db} / \mathrm{db}$ and ob/ob mice; $* * P<0.05$ versus C57BL/6 mice). Mice types: C57BL/6, wild type; $\mathrm{ob} / \mathrm{ob}, \mathrm{db} / \mathrm{db}$ genetically obese and diabetic; $\mathrm{ob}^{+} / \mathrm{ob}^{-}, \mathrm{db}^{+} / \mathrm{db}^{-}$, complementary heterozygous; DIO, diet-induced obese.

A

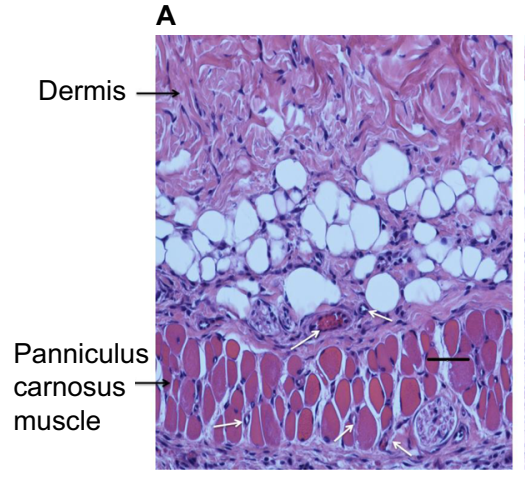

B

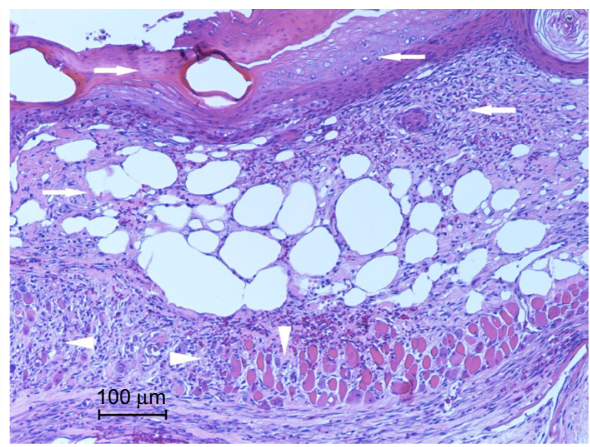

C

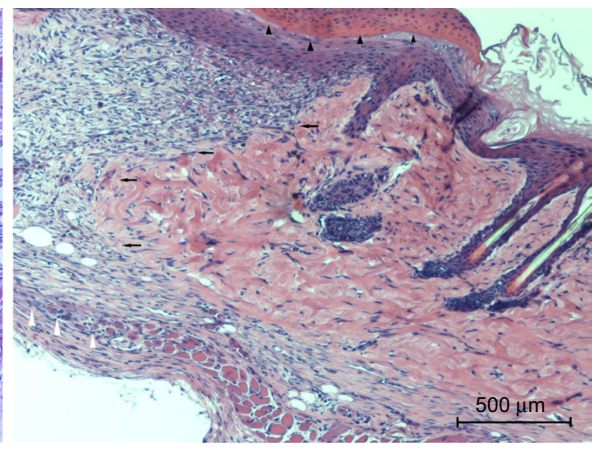

Figure 3 Histopathology of lean and obese flaps at day 10.

Notes: (A) High magnification (200x, black scale bar $50 \mu \mathrm{m})$ of $\mathrm{db} / \mathrm{db}$ flap demonstrating viable dermis and muscle with extensive neovascularization (white arrows). (B) Hematoxylin and eosin stain (100× magnification) of C57BL/6 (wild type) distal flap section revealing epidermal (presence of eschar without viable keratinocytes) and dermal (loss of organized collagen fibers) necrosis (arrows) and scattered panniculus muscle bundle necrosis (loss of symmetric muscle bundles; arrowheads). (C) Identical stain (I00x magnification) of DIO flap section at the junction of flap necrosis and healthy surrounding back tissue (black arrows delineating junction). Note the hyperproliferative tongue of epidermis elevating the necrotic eschar (black arrowheads at margin of eschar and proliferative epidermis). White arrowheads mark the junction of deep flap necrosis (panniculus muscle necrosis) with healthy surrounding nonflap muscle. Abbreviation: DIO, diet-induced obese. 


\section{Model of ischemia and real-time myocutaneous flap perfusion}

FITC-dextran perfusion demonstrated that the blood supply to the back skin and panniculus muscle of lean and obese mice is segmentally arranged and originates from vertical feeding vessels as well as intercostal and lumbar arteries with a central zone of anastomosis. ${ }^{15}$ This spatial distribution of control perfusion was confirmed by laser speckle examination and three-dimensional image reconstruction using MatLab software (Figure 4). Therefore, a narrow flap width $(1 \mathrm{~cm})$ was chosen which was anatomically centered within the central zone of vascular anastomosis to produce maximal distal flap ischemia to differentiate changes in revascularization in lean and obese mice.

Preoperatively, respective global back skin perfusion was consistent across cranial, central, and caudal ROIs in lean and obese mice. However, preoperative back skin perfusion values were significantly higher in genetically obese mice (mean range 395-430 PU) compared to wild type (mean $210 \mathrm{PU}$ ), heterozygous (mean range 205-215 PU), and DIO (mean 210 PU) mice (Figure 5).

A
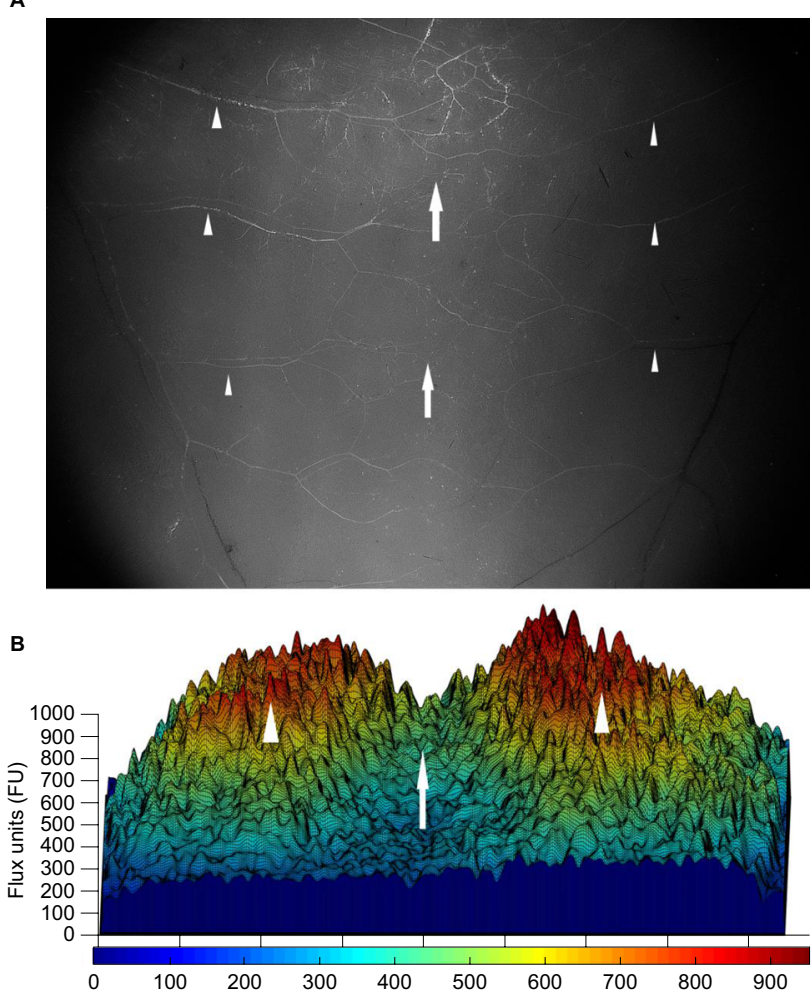

Figure 4 Blood supply of the back skin and muscle of a genetically obese mouse. Notes: (A) Representative fluorescent image of unoperated genetically diabetic $(\mathrm{db} / \mathrm{db})$ mouse back skin demonstrating the segmental blood vessels (arrowheads) and central zone of anastomosis (arrows). Photomicrograph taken using a fluorescent dissecting microscope (100× magnification). (B) Three-dimensional reconstruction of preoperative laser speckle image of $\mathrm{db} / \mathrm{db}$ mouse back skin confirming the spatial distribution of control perfusion (arrowheads) and central zone of anastomosis (arrow). The color scale illustrates variations in perfusion from maximum (red) to minimum (blue).
Immediately after flap creation (post-op or day 0), flap perfusion declined in a cranial to caudal gradient in all groups. Over the 10-day study period, in genetically obese mice, laser imaging documented markedly increased perfusion in each ROI at all time points compared to immediate postoperative values, an indication of flap revascularization. By day 10 , cranial and central ROI perfusion in $\mathrm{db} / \mathrm{db}$ and ob/ob flaps actually surpassed preoperative or baseline values (Figure 5).

In contrast, in wild type and heterozygous mice, cranial, central, and caudal ROI perfusion increased from immediate postoperative values, peaked at day 2 , and subsequently remained unchanged $\left(\mathrm{db}^{+} / \mathrm{db}^{-}\right.$mice $)$or declined to values that were less than preoperative values (wild type, $\mathrm{ob}^{+} / \mathrm{ob}^{-}$mice) by day 10 . In DIO mice, there was no significant increase in perfusion in any ROI over the 10-day interval, suggesting lack of functional revascularization (Figure 5).

\section{Microvascular density and anatomy}

Control vessel counts and surface area estimates were comparable in $\mathrm{db} / \mathrm{db}$ and ob/ob mice and significantly higher compared with values in wild type, heterozygous, and DIO mice, consistent with preoperative laser speckle data. By day 10, in lean and obese mice, there was an increase in proximal and distal flap vessel number and surface area compared to control back tissue, with the values recorded in genetically obese mice significantly higher than those in lean and DIO mice (Figure 6).

Quantification and localization of the microvasculature corroborated the changes in flap perfusion demonstrated by laser speckle contrast imaging. Dilatation of existing cranial and central region vessels and new vessel growth or neovascularization from the recipient paraspinal muscle vasculature into the distal flap were responsible for flap revascularization and viability in genetically obese mice. As a result of the large contribution of the deep flap ( $>750 \mu \mathrm{m}$ from surface) subcutaneous and panniculus muscle tissue vascularity to global perfusion, laser speckle measurement of surface perfusion ( $\sim 500 \mu \mathrm{m}$ depth) underestimated the dramatic increases in $\mathrm{db} / \mathrm{db}$ and ob/ob full-thickness flap vascularity. Conversely, in wild type, heterozygous, and DIO mice, there was limited dilation of proximal flap vasculature and minimal neovascularization resulting in distal flap myocutaneous necrosis, most severe in DIO mice (Figure 6).

\section{Macrophage quantification and localization}

F4/80 gene expression and its cell surface protein presence were utilized to quantify and localize macrophage presence in control and day 10 flap tissues of lean and obese mice. 
A

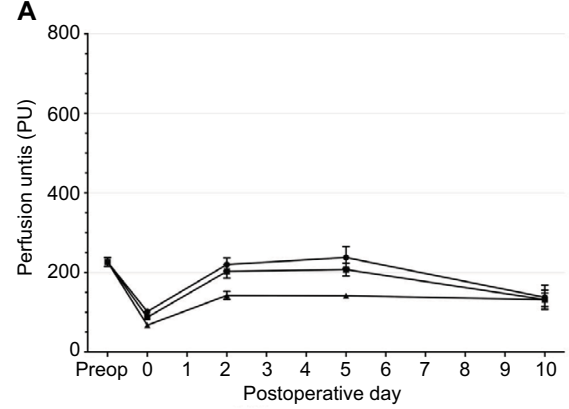

- C57BL/6 cranial - C57BL/6 central - C57BL/6 caudal

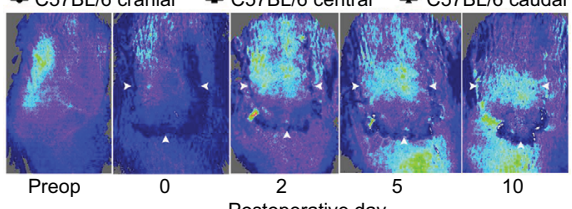

Postoperative day

01002003004005006007008009001000

C
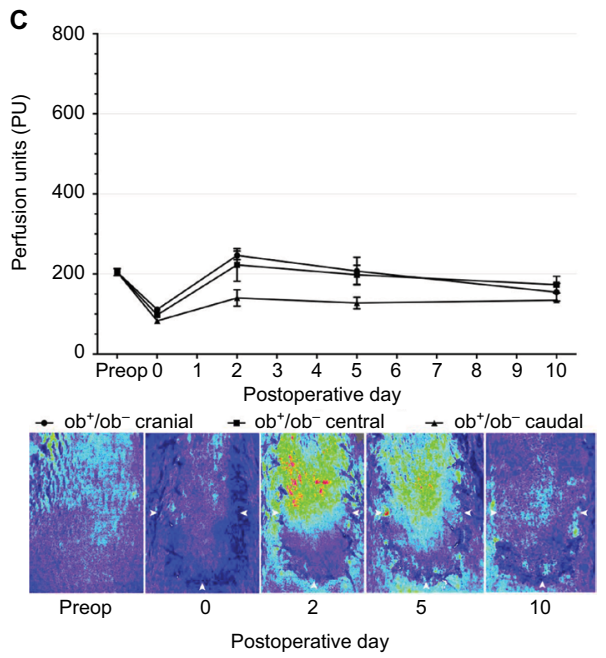

E

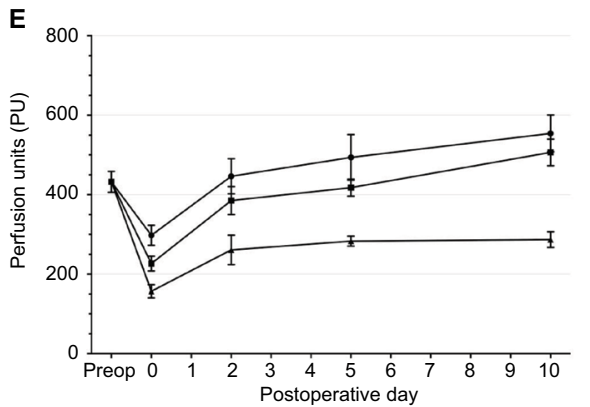

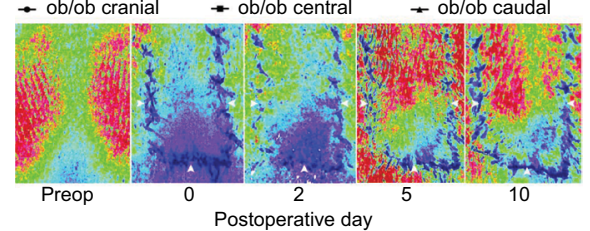

B

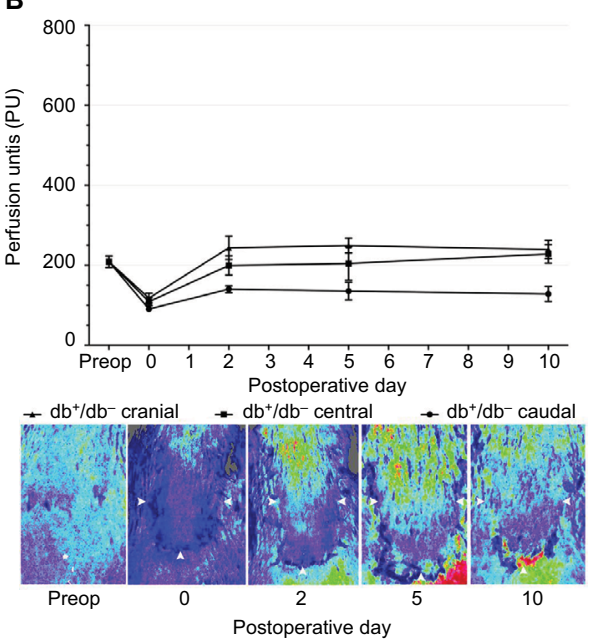

D

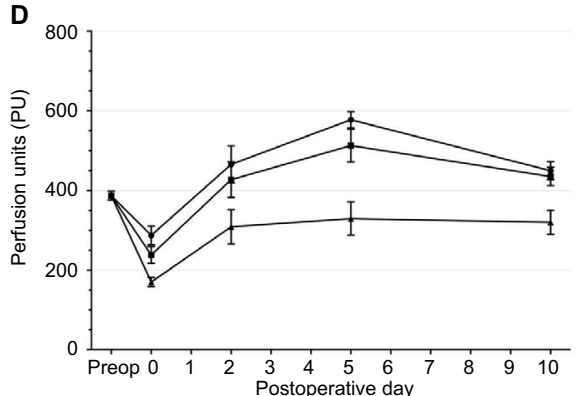

$\rightarrow \mathrm{db} / \mathrm{db}$ cranial $\rightarrow \mathrm{db} / \mathrm{db}$ central $\rightarrow \mathrm{db} / \mathrm{db}$ caudal

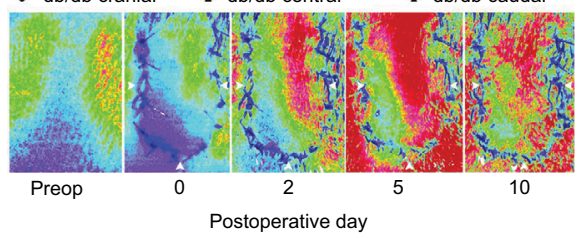

$\mathbf{F}$
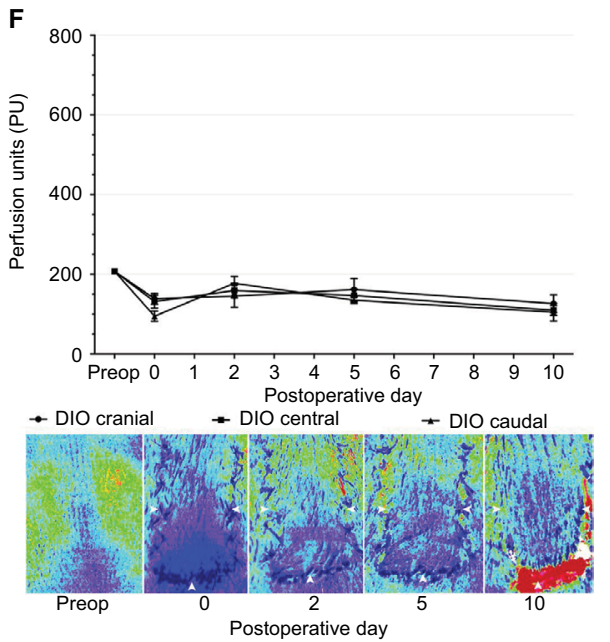

Figure 5 Quantitative laser speckle perfusion versus time and representative laser speckle contrast images of lean and obese flaps for $C 5 B L / 6(A), d b^{+} / d b^{-}(B), o b^{+} / o b^{-}(C)$, $\mathrm{db} / \mathrm{db}(\mathbf{D})$, ob/ob (E), and DIO (F).

Notes: The color scale illustrates variations in perfusion from maximum (red) to minimum (blue). Flap boundaries are outlined by arrowheads. Note the functional revascularization over time in genetically obese mice ( $\mathbf{D}$ and $\mathbf{E}$ compare day 0 to day 10 images). Note the lack of revascularization in DIO mice (F) characterized by flap dehiscence and exposure of highly perfused paraspinal musculature (red). Mice types: $\mathrm{C}^{2} \mathrm{BL} / 6$, wild type; ob/ob, db/db genetically obese and diabetic; ob $/ \mathrm{ob}^{-}$, $\mathrm{db}^{+} / \mathrm{db}^{-}$, complementary heterozygous; DIO, diet-induced obese.

Abbreviation: preop, preoperative. 


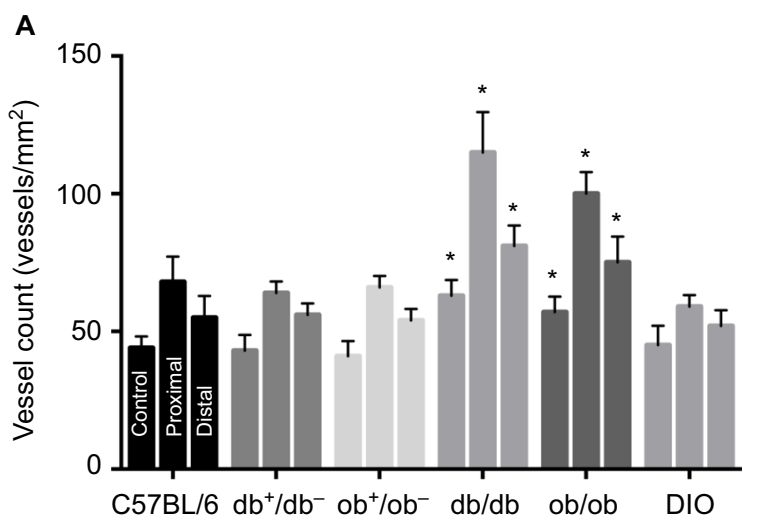

C

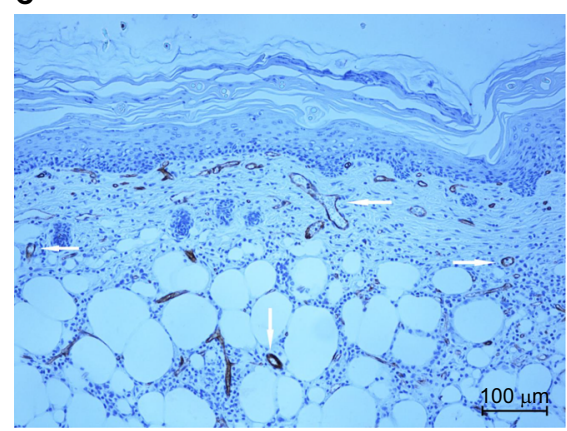

D

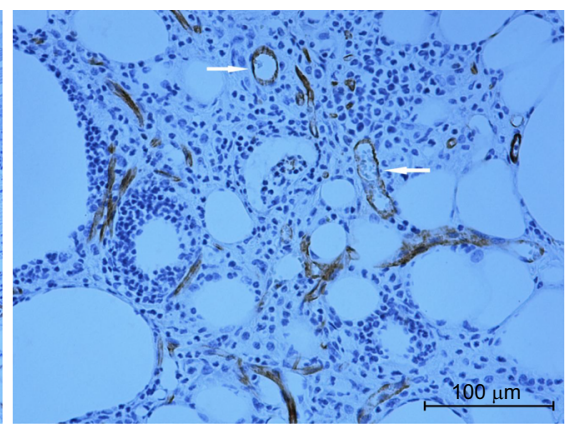

\section{B}

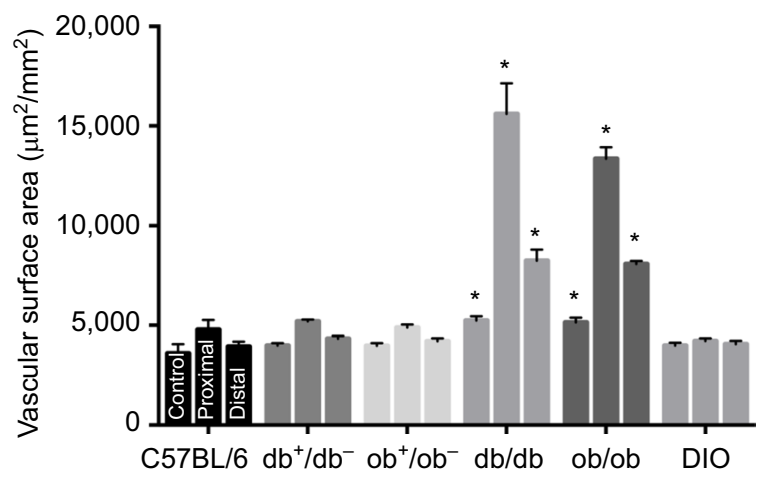

E

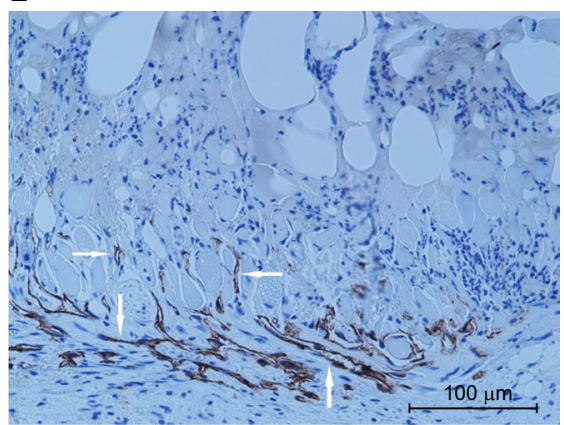

Figure 6 Flap microvascular density and anatomy in lean and obese mice.

Notes: (A) Quantitative vessel count of unoperated mouse back myocutaneous tissue (control) and proximal and distal regions of flaps at day 10 ( $* P<0.05$ versus respective heterozygous controls). (B) Quantitative vascular surface area estimate of control and proximal and distal regions of flaps at day $10(* P<0.05$ versus respective heterozygous controls). (C) Photomicrograph of day 10 proximal db/db flap demonstrating enlarged proximal vessels (arrows) in dermis and subcutaneous fat (CD-3I immunostaining, endothelium stains brown; 100x magnification). (D) High-magnification image (200x) of proximal db/db flap subcutaneous tissue depicting multiple enlarged proximal vessels (arrows). (E) Photomicrograph of day 10 proximal DIO flap (200x magnification) illustrating minimal proximal flap vasculature with new vessel growth limited to recipient bed granulation tissue and panniculus muscle (arrows). Mice types: C57BL/6, wild type; ob/ob, db/db genetically obese and diabetic; ob ${ }^{+} / o b^{-}, d^{+} / d^{-}$, complementary heterozygous; DIO, diet-induced obese.

F4/80 is an antigenic marker present on murine macrophages, which is constitutively expressed throughout adult life and is absent on neutrophils. ${ }^{17}$ In unoperated or control myocutaneous tissues, there was no significant difference in macrophage presence between lean and obese mice. Macrophages were located in the dermis, subcutaneous fat, panniculus muscle, and its investing fascia in all groups. By day 10, there was a significant increase in the presence of macrophage in both lean and obese mice compared to the respective controls, with the greatest increases in $\mathrm{ob} / \mathrm{ob}, \mathrm{db}^{+} / \mathrm{db}^{-}$, and DIO mice. At day 10 , in lean and genetically obese mice, macrophages were present in the flap subcutaneous, panniculus muscle, and granulation tissue, with little change in dermal content. In DIO mice, macrophages were primarily present within the recipient bed granulation tissue (Figure 7).

\section{Tissue gene expression}

To investigate baseline (prior to surgery) differences in gene expression between genetically obese and lean heterozygous mice, reverse transcription (RT) PCR array was performed to analyze unoperated $\mathrm{db} / \mathrm{db}$ and $\mathrm{db}^{+} / \mathrm{db}^{-}$back tissues for the expression of a focused panel of genes involved in wound chemotaxis, inflammation, and angiogenic signaling. In addition to an increase in leptin gene expression, genes involved in angiogenesis, neutrophil and monocyte chemotaxis, and hypoxia sensing were upregulated in unoperated $\mathrm{db} / \mathrm{db}$ mice compared to heterozygous controls. Genes involved in endothelial differentiation and vascular remodeling were downregulated in $\mathrm{db} / \mathrm{db}$ mice (Figure $8 \mathrm{~A}$ and $\mathrm{B}$ ). There was no significant up or downregulation in expression of the remaining array genes.

To determine whether obesity induced by leptin/leptin receptor axis deficiency or ingestion of a high-fat diet influenced the transcription of genes involved in wound neovascularization, probe-specific quantitative RT-PCR was performed on control (unoperated) and day 10 lean and obese flap tissues. At day 10 (Figure 8A), vascular endothelial growth factor a (VEGFa), VEGF receptor-2 (VEGFR-2), and Delta-like ligand 4 (D114) gene expression remained elevated in lean mice (wild type and heterozygotes) compared 

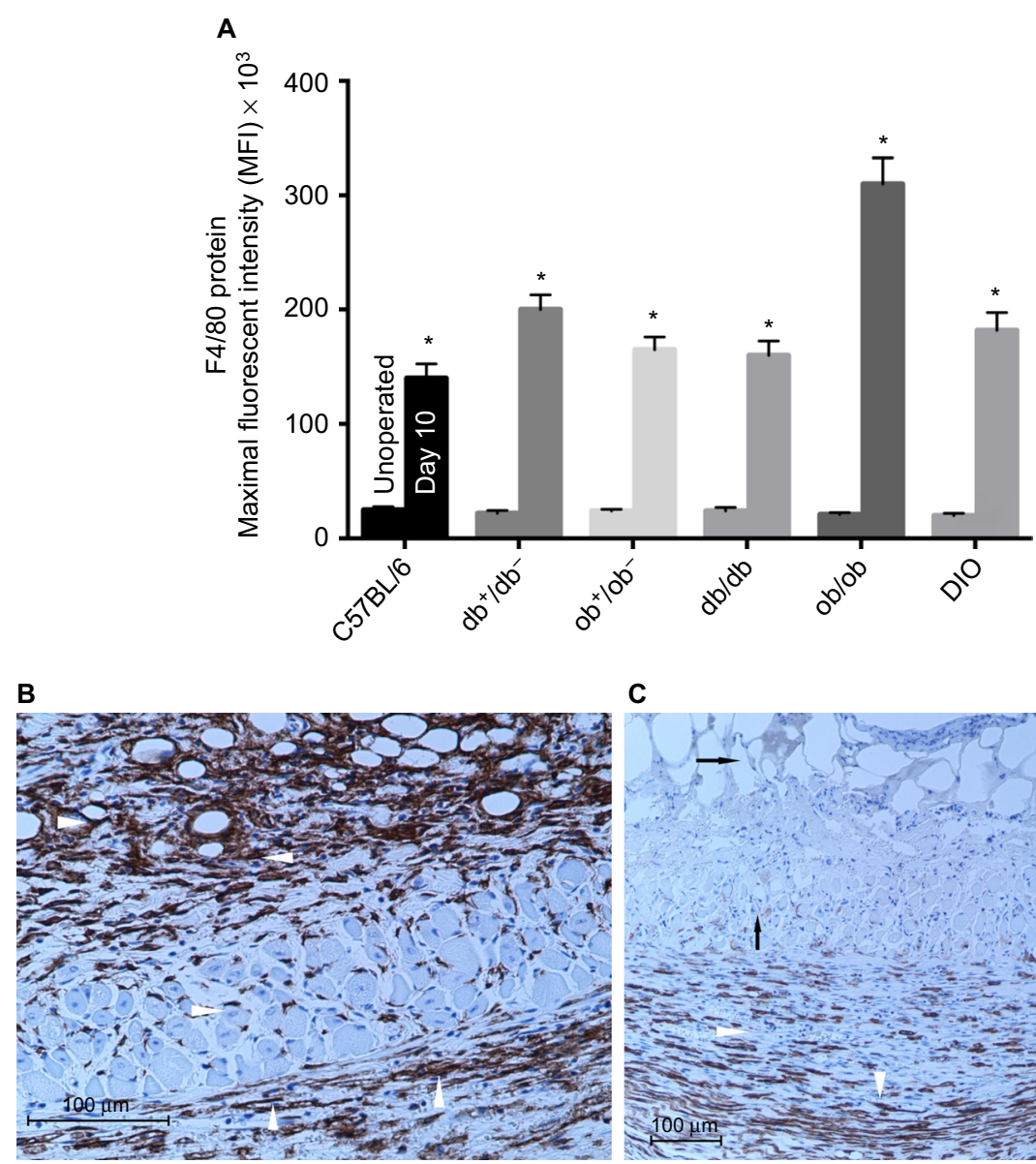

C

Figure 7 Flap macrophage quantification and localization in lean and obese mice.

Notes: (A) F4/80 protein maximal fluorescent intensity of unoperated mouse back myocutaneous (control) and day 10 flap tissues $(* P<0.05$ versus respective unoperated control). (B) Photomicrograph of day 10 ob/ob flap depicting macrophages within the subcutaneous, muscle, and granulation tissues (arrowheads) (F4/80 bright-field immunostaining, macrophages stain brown; 200x magnification). (C) Photomicrograph of day 10 DIO flap (F4/80 bright-field immunostaining, macrophages stain brown; $100 \times$ magnification) revealing macrophages within the recipient bed granulation tissue (white arrowheads). Note the necrotic subcutaneous fat and scattered panniculus muscle (black arrows). Mice types: C57BL/6, wild type; ob/ob, db/db genetically obese and diabetic; $\mathrm{ob}^{+} / \mathrm{ob}^{-}, \mathrm{db}^{+} / \mathrm{db}^{-}$, complementary heterozygous; DIO, diet-induced obese.

to their respective unoperated controls. However, sustained angiogenic gene expression was not evident in genetically obese and DIO mice. At day 10, the expression of these genes either returned toward baseline or was downregulated in obese mice (Figure 8C).

\section{Discussion}

Approximately $8 \%$ of Americans are morbidly obese, and an alarming number are overweight or obese. Massive weight loss nearly eliminates the comorbidities (diabetes, hypertension, and hyperlipidemia) associated with obesity; however, wound healing complications remain increased in these patients after body-contouring procedures. ${ }^{18}$ Despite the return of inflammatory markers to normal levels following massive weight loss, an increased risk of postoperative wound infection, hematoma, seroma, and skin necrosis remains. Several studies have identified and detailed the management of these complications; however, preoperative identification of patients at increased risk of impaired healing remains inconsistent, likely a result of the lack of understanding of the mechanism responsible for the altered healing..$^{19,20}$

Obesity is a complex disease involving interactions between genetic predisposition and environmental factors. ${ }^{21}$ Hence, this is the basis for the present investigation of wound revascularization in genetic and nutritionally induced obese mice. Early papers in the field of wound healing established the use of the $\mathrm{db} / \mathrm{db}$ and ob/ob mouse as a model of impaired reepithelialization of an excisional wound. ${ }^{22,23}$ However, the limitations of genetically obese mice as a model of impaired healing deserve attention.

A single mutation results in complete loss of biologically active leptin production (ob/ob) or leptin receptor function $(\mathrm{db} / \mathrm{db})$ leading to hyperphagia along with variable hyperglycemia, hypercortisolism, and sterility. ${ }^{24}$ These mice develop morbid obesity and insulin resistance. ${ }^{25} \mathrm{In}$ ob/ob mice, the hyperglycemia is transient and mild compared to $\mathrm{db} / \mathrm{db}$ 
A

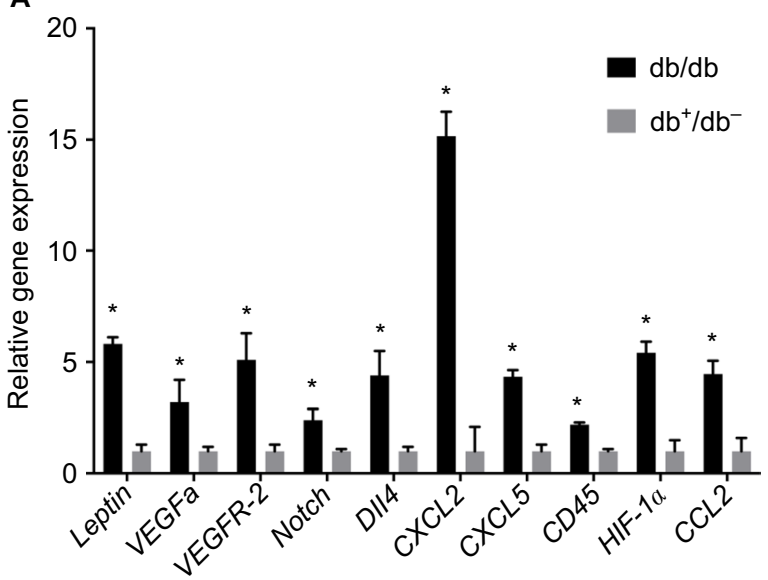

B

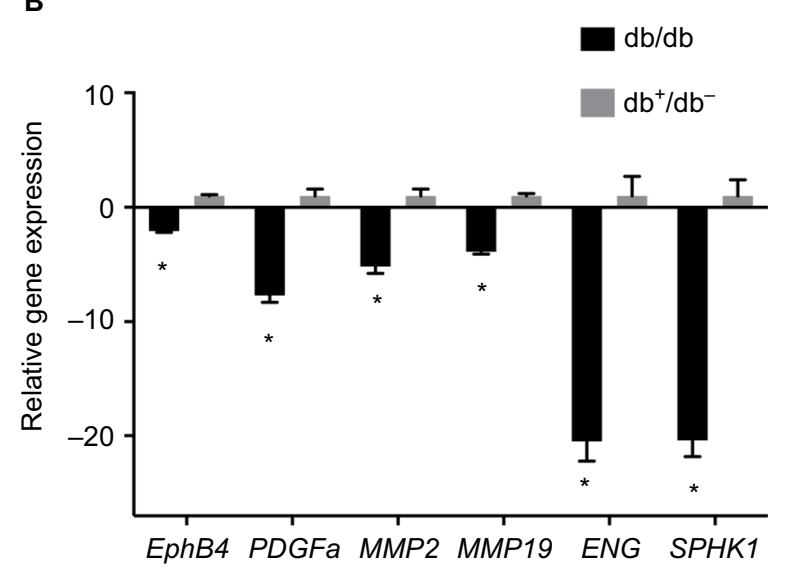

C

\begin{tabular}{|c|c|c|c|c|c|c|}
\hline & C57BL/6 & $\mathrm{db}^{+} / \mathrm{db}^{-}$ & $\mathrm{ob} / \mathrm{ob}^{-}$ & $\mathrm{db} / \mathrm{db}$ & ob/ob & DIO \\
\cline { 2 - 7 } VEGFa & 1.76 & 1.52 & 1.59 & 0.96 & 1.13 & 0.74 \\
& $1.68-1.83$ & $1.49-1.55$ & $1.15-1.97$ & $0.94-0.98$ & $1.00-1.24$ & $0.59-1.86$ \\
& $P=0.01$ & $P=0.004$ & $P=0.06$ & $P=0.62$ & $P=0.28$ & $P=0.06$ \\
\hline \multirow{3}{*}{ VEGFR-2 } & 2.45 & 1.76 & 1.78 & 0.40 & 1.13 & 0.91 \\
& $2.36-2.58$ & $1.61-2.05$ & $1.71-1.90$ & $0.39-0.41$ & $1.08-1.22$ & $0.89-0.93$ \\
& $P=0.001$ & $P=0.025$ & $P=0.002$ & $P<0.001$ & $P=0.29$ & $P=0.46$ \\
\hline \multirow{3}{*}{ Notch } & 2.76 & 1.21 & 1.14 & 0.33 & 0.68 & 1.21 \\
& $2.20-3.23$ & $1.20-1.22$ & $0.93-2.73$ & $0.32-0.34$ & $0.63-0.76$ & $0.79-1.55$ \\
& $P=0.026$ & $P=0.47$ & $P=0.77$ & $P<0.001$ & $P=0.02$ & $P=0.44$ \\
\hline \multirow{3}{*}{ DII4 } & 2.25 & 3.68 & 2.14 & 0.40 & 1.75 & 1.20 \\
& $2.01-2.68$ & $2.85-4.40$ & $2.10-2.17$ & $0.38-0.40$ & $1.64-1.84$ & $0.89-1.45$ \\
& $P=0.003$ & $P=0.008$ & $P=0.001$ & $P=0.002$ & $P=0.004$ & $P=0.38$ \\
\hline \multirow{3}{*}{ F4/80 } & 1.78 & 3.96 & 2.80 & 2.23 & 8.13 & 3.47 \\
& $1.44-2.71$ & $3.73-4.11$ & $2.38-3.07$ & $1.68-3.65$ & $7.47-8.56$ & $3.03-3.80$ \\
& $P=0.045$ & $P=0.005$ & $P=0.006$ & $P=0.001$ & $P=0.0002$ & $P=0.0005$ \\
\hline
\end{tabular}

Fold change $95 \% \mathrm{Cl}$

$P$-value

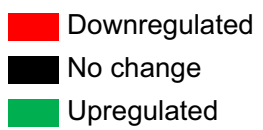

Figure 8 (A) Unoperated back tissue array of upregulated gene expression in $\mathrm{db} / \mathrm{db}$ mice $\left({ }^{*}<0.05\right.$ versus $\mathrm{db}^{+} / \mathrm{db}^{-}$unoperated back tissue); (B) unoperated back tissue array of downregulated gene expression in $\mathrm{db} / \mathrm{db}$ mice $\left(* P<0.05\right.$ versus $\mathrm{db}^{+} / \mathrm{db}^{-}$unoperated back tissue). (C) Day 10 flap gene expression in lean and obese mice $(P<0.05$ versus

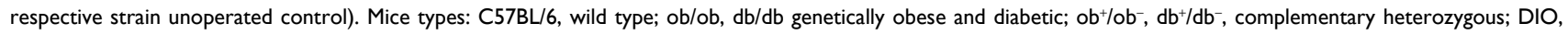
diet-induced obese.

Abbreviations: $\mathrm{Cl}$, confidence interval; DII4, Delta-like ligand 4; ENG, endoglin; EphB4, ephrin type-B receptor 4; HIF-I $\alpha$, hypoxia-inducible factor I alpha; MMP2, matrix metalloproteinase 2; MMPI9, matrix metalloproteinase 19; PDGFa, platelet-derived growth factor a; SPHKI, sphingosine kinase I; VEGFa, vascular endothelial growth factor a; VEGFR-2, VEGF receptor 2.

mice, and by 6 months of age, blood glucose levels in ob/ ob mice are comparable to control mice. ${ }^{26}$ Recent studies have demonstrated no significant histologic difference in the closure of splinted excisional wounds in genetically obese mice compared to heterozygous controls. The authors suggested that the reduction in excisional wound closure in $\mathrm{db} / \mathrm{db}$ and $\mathrm{ob} / \mathrm{ob}$ mice seemed to be a function of the size of the mice producing a constant stretch on the skin. The dramatic increase in trunk circumference leads to a wound healing deficit which is largely independent of diabetes and different than the impaired healing observed in human type 2 diabetes characterized by decreased or impaired growth factor production, angiogenic response, macrophage function, collagen accumulation, and keratinocyte migration and proliferation. ${ }^{27-29}$ Investigators have documented that the impairment in excisional wound closure in $\mathrm{db} / \mathrm{db}$ and ob/ob mice does not correlate with the magnitude of hyperglycemia..$^{30,31}$

Ischemia-reperfusion injury, while extensively studied in organs such as the heart and brain, has received little attention in the skin. Therefore, our established model of graded myocutaneous ischemia was utilized to investigate the differences in wound revascularization in lean and obese mice. Our research unexpectedly documents effective 
myocutaneous revascularization of ischemic tissue in genetically obese mice independent of serum glucose values. Prior to surgery, genetically obese mice had higher myocutaneous perfusion and microvascular density compared to wild type, heterozygous, and DIO mice. At equivalent body weight, wound neovascularization was dramatically reduced in dietinduced obese mice compared to genetically obese mice resulting in full-thickness necrosis of skin, subcutaneous fat, and panniculus carnosus muscle in DIO mice. Despite comparable preoperative perfusion and vascular density, flap revascularization was significantly impaired in DIO mice compared to lean mice.

At day 10, reduced or downregulated expression of genes involved in angiogenesis was evident in genetically obese and DIO flaps, possibly a result of successful distal flap revascularization and a lack of further ischemic stimulus in genetically obese mice, and irreversible flap ischemia and necrosis in DIO mice. In contrast, sustained increases in angiogenic gene expression were documented in lean mice flaps at day 10 reflecting sustained flap angiogenesis due to persistent and reversible distal flap ischemia.

An early event of a wound healing response is infiltration of inflammatory cells at the wound site. This inflammatory response includes accumulation of macrophages which modulate healing through their inflammatory and reparative phenotypes. ${ }^{32}$ In preoperative tissue, F4/80 protein expression revealed no difference in the presence of macrophage between lean and obese mice. However, F4/80 gene and protein expression confirmed a significant increase in the quantity of macrophages in all mice by day 10 , with the greatest increases in ob/ob, $\mathrm{db}^{+} / \mathrm{db}^{-}$, and DIO mice. PCR array technology documented a preoperative increase in myocutaneous leptin gene expression, and dramatic differences in the expression of genes involved in angiogenesis, inflammatory cell chemotaxis, hypoxia sensing, and endothelial differentiation between $\mathrm{db} / \mathrm{db}$ and heterozygous control mice, suggesting the $\mathrm{db} / \mathrm{db}$ mouse skin and muscle may be "primed" for wound revascularization.

\section{Conclusion}

Utilizing this ischemia-revascularization wound healing model and laser speckle imaging technology, further investigation on the effects of the leptin/receptor axis and resident and recruited cellular gene expression on the spatial and temporal change in flap revascularization has been planned in an attempt to gain a better understanding of the differences in wound microvascular biology in lean and genetically and DIO states. The role of the adipocyte and its associated vasculature may provide new and unexpected insights into ways adipose tissue biology can be targeted to improve wound healing.

\section{Acknowledgment}

The research presented in this article was supported in part by a grant (SRIA) from the Department of Surgery at the University of New Mexico HSC.

\section{Author contributions}

All authors contributed toward study design, acquisition and interpretation of data, drafting and critically revising the paper, gave final approval of the version to be published, and agree to be accountable for all aspects of the work.

\section{Disclosure}

The authors report no conflicts of interest in this work.

\section{References}

1. World Health Organization. Obesity and overweight fact sheet. The World Health Organization website; 2009. Available from: http:// www.who.int/dietphysicalactivity/media/en/gsfs_obesity.pdf. Accessed June 10, 2016

2. Cao Y. Adipose tissue angiogenesis as a therapeutic target for obesity and metabolic diseases. Nat Rev Drug Disc. 2010;9:107-115.

3. Wang CY, Liao JK. A mouse model of diet-induced obesity and insulin resistance. Methods Mol Biol. 2012;821:421-433.

4. Galiano RD, Michaels J, Dobryansky M, Levine P, Gurtner GC. Quantitative and reproducible murine model of excisional wound healing. Wound Rep Reg. 2004;12:485-492.

5. Eming SA, Martin P, Tomic-Canic M. Wound repair and regeneration: mechanisms, signaling, and translation. Sci Transl Med. 2014;6(265):1-16.

6. Nunan R, Harding KG, Martin P. Clinical challenges of chronic wounds: searching for an optimal animal model to recapitulate their complexity. Dis Model Mech. 2014;7:1205-1213.

7. Wetzler C, Kampfer H, Stallmeyer B, Pfeilschifter J, Frank S. Large and sustained induction of chemokines during impaired wound healing in the genetically diabetic mouse: prolonged persistence of neutrophils and macrophages during the late phase of repair. $J$ Invest Dermatol. 2000;115(2):245-253.

8. Werner S, Breeden M, Hubner G, Greenhalgh DG, Longaker MT. Induction of keratinocyte growth factor expression is reduced and delayed during wound healing in the genetically diabetic mouse. J Invest Dermatol. 1994;103(4):469-473.

9. Dhall S, Do DC, Garcia M, Kim J, Martins-Green M. Generating and reversing chronic wounds in diabetic mice by manipulating wound redox parameters. J Diabetes Res. 2014;15:1-18.

10. Wang XQ, Lee S, Wilson H, Seeger M, Paller AS. Ganglioside GM3 depletion reverses impaired wound healing in diabetic mice by activating IGF-1 and insulin receptors. J Invest Dermatol. 2014;134:1446-1455.

11. Seitz O, Schurmann C, Hermes N, Muller E, Pfeilschifter J, Frank S, Goren I. Wound healing in mice with high-fat diet or ob gene-induced diabetes-obesity syndromes: a comparative study. Exp Diabetes Res. 2010;1:1-15.

12. Halaas JL, Gajiwala KS, Maffei M, Cohen SL, Friedman JM. Weightreducing effects of the plasma protein encoded by the obese gene. Science. 1995;269:543-546.

13. Clark RM, Cicotte KN, McGuire PG, Hedberg-Dirk EL, Howdieshell TR. The effect of projection microstereolithographic fabricated implant geometry on myocutaneous revascularization. Surg Sci. 2014;5:513-525. 
14. Khan B, Rangasamy S, McGuire PG, Howdieshell TR. The role of monocyte subsets in myocutaneous revascularization. J Surg Res. 2013;183:963-975.

15. McGuire PG, Howdieshell TR. The importance of engraftment in flap revascularization: confirmation by laser speckle perfusion imaging. $J$ Surg Res. 2010;164:e201-e212.

16. Howdieshell TR, McGuire L, Maestas J, McGuire PG. Pattern recognition receptor gene expression in ischemia-induced flap revascularization. Surgery. 2011;150:418-428.

17. Taylor PR, Martinez-Pornares L, Stacey M. Macrophage receptors and immune recognition. Annu Rev Immunol. 2005;23:901-950.

18. Coon D, Gusenoff JA, Kannan N, Rubin JP. Body mass and surgical complications in the postbariatric reconstructive patient: analysis of 511 cases. Ann Surg. 2009;249:397-401.

19. Gusenoff JA, Rubin JP. Plastic surgery after weight loss: Current concepts in massive weight loss surgery. Aesthet Surg J. 2008;28:452-455.

20. Michaels JV, Coon D, Rubin JP. Complications in postbariatric body contouring: postoperative management and treatment. Plast Reconstr Surg. 2011;127:1693-1700.

21. Hardy OT, Czech MP, Corvera S. What causes the insulin resistance underlying obesity? Curr Opin Endocrinol Diabetes Obes. 2012;19:81-87.

22. Goodson WH, Hunt TK. Wound collagen accumulation in obese hyperglycemic mice. Diabetes. 1986;35(4):491-495.

23. Greenhalgh DG, Sprugel KH, Murray MJ, Ross R. PDGF and FGF stimulate wound healing in the genetically diabetic mouse. Am J Pathol. 1990;136(6):1235-1246.
24. Wang B, Chandrasekera PC, Pippin JJ. Leptin and leptin-deficient rodent models: relevance for human type 2 diabetes. Curr Diabetes Rev. 2014;10:131-145.

25. Sainz N, Barrenetxe J, Moreno-Aliaga MJ, Martinez JA. Leptin resistance and diet-induced obesity: central and peripheral actions of leptin. Metabolism. 2015;64:35-46.

26. Clee SM, Attie AD. The genetic landscape of type 2 diabetes in mice. Endocrine Rev. 2007;28(1):48-83.

27. Fang RC, Kryger ZB, Buck DW, Galiano RD, Mustoe TA. Limitations of the $\mathrm{db} / \mathrm{db}$ mouse in translational wound healing research: is the NONcNZO10 polygenic mouse model superior? Wound Rep Reg. 2010;18:605-613.

28. Park SA, Teixeira LBC, Raghunathan VK, McAnulty J, Murphy CJ. Full-thickness splinted skin wound healing models in $\mathrm{db} / \mathrm{db}$ and heterozygous mice: implications for wound healing impairment. Wound Rep Reg. 2014;22:368-380.

29. Brem H, Tomic-Canic M. Cellular and molecular basis of wound healing in diabetes. J Clin Invest. 2007;117(5):1219-1222.

30. Trousdale RK, Jacobs S, Simhaee DA, Wu JK, Lustbader JW. Wound closure and metabolic parameter variability in a $\mathrm{db} / \mathrm{db}$ mouse model for diabetic ulcers. J Surg Res. 2009;151:100-107.

31. Berdal M, Jenssen T. No association between glycemia and wound healing in an experimental db/db mouse model. ISRN Endocrinol. 2013: $1-6$.

32. Mizra R, DiPietro LA, Koh TJ. Selective and specific macrophage ablation is detrimental to wound healing in mice. Am J Pathol. 2009;175(6):2454-2462.

\section{Publish your work in this journal}

Diabetes, Metabolic Syndrome and Obesity: Targets and Therapy is an international, peer-reviewed open-access journal committed to the rapid publication of the latest laboratory and clinical findings in the fields of diabetes, metabolic syndrome and obesity research. Original research, review, case reports, hypothesis formation, expert opinion and commentaries are all considered for publication. The manuscript management system is completely online and includes a very quick and fair peer-review system, which is all easy to use. Visit http://www.dovepress.com/testimonials.php to read real quotes from published authors. 